Research Article

\title{
On Unification of the Strong Convergence Theorems for a Finite Family of Total Asymptotically Nonexpansive Mappings in Banach Spaces
}

\author{
Farrukh Mukhamedov and Mansoor Saburov \\ Department of Computational \& Theoretical Sciences, Faculty of Sciences, International Islamic \\ University Malaysia, P.O. Box 141, 25710, Kuantan, Malaysia \\ Correspondence should be addressed to Farrukh Mukhamedov, far75m@yandex.ru \\ Received 5 January 2012; Revised 10 March 2012; Accepted 12 March 2012 \\ Academic Editor: Giuseppe Marino
}

Copyright (C) 2012 F. Mukhamedov and M. Saburov. This is an open access article distributed under the Creative Commons Attribution License, which permits unrestricted use, distribution, and reproduction in any medium, provided the original work is properly cited.

\begin{abstract}
We unify all known iterative methods by introducing a new explicit iterative scheme for approximation of common fixed points of finite families of total asymptotically I-nonexpansive mappings. Note that such a scheme contains a particular case of the method introduced by $(\mathrm{C}$. E. Chidume and E. U. Ofoedu, 2009). We construct examples of total asymptotically nonexpansive mappings which are not asymptotically nonexpansive. Note that no such kind of examples were known in the literature. We prove the strong convergence theorems for such iterative process to a common fixed point of the finite family of total asymptotically I-nonexpansive and total asymptotically nonexpansive mappings, defined on a nonempty closed-convex subset of uniformly convex Banach spaces. Moreover, our results extend and unify all known results.
\end{abstract}

\section{Introduction}

Let $K$ be a nonempty subset of a real normed linear space $X$, and let $T: K \rightarrow K$ be a mapping. Denote by $F(T)$ the set of fixed points of $T$, that is, $F(T)=\{x \in K: T x=x\}$. Throughout this paper, we always assume that $X$ is a real Banach space and $F(T) \neq \emptyset$. Now let us recall some known definitions.

Definition 1.1. A mapping $T: K \rightarrow K$ is said to be

(i) nonexpansive if $\|T x-T y\| \leq\|x-y\|$ for all $x, y \in K$,

(ii) asymptotically nonexpansive if there exists a sequence $\left\{\lambda_{n}\right\} \subset[1, \infty)$ with $\lim _{n \rightarrow \infty} \lambda_{n}=1$ such that $\left\|T^{n} x-T^{n} y\right\| \leq \lambda_{n}\|x-y\|$ for all $x, y \in K$ and $n \in \mathbb{N}$, 
(iii) asymptotically nonexpansive in the intermediate sense, if it is continuous and the following inequality holds:

$$
\limsup _{n \rightarrow \infty} \sup _{x, y \in K}\left(\left\|T^{n} x-T^{n} y\right\|-\|x-y\|\right) \leq 0
$$

Remark 1.2. Observe that if we define

$$
a_{n}:=\sup _{x, y \in K}\left(\left\|T^{n} x-T^{n} y\right\|-\|x-y\|\right), \quad \sigma_{n}:=\max \left\{0, a_{n}\right\},
$$

then $\sigma_{n} \rightarrow 0$ as $n \rightarrow \infty$, and (1.1) reduces to

$$
\left\|T^{n} x-T^{n} y\right\| \leq\|x-y\|+\sigma_{n}, \quad \forall x, y \in K, n \geq 1
$$

In $[1,2]$, Browder studied the iterative construction for fixed points of nonexpansive mappings on closed and convex subsets of a Hilbert space. Note that for the past 30 years or so, the study of the iterative processes for the approximation of fixed points of nonexpansive mappings and fixed points of some of their generalizations have been flourishing areas of research for many mathematicians (see for more details $[3,4]$ ).

The class of asymptotically nonexpansive mappings was introduced by Goebel and Kirk [5] as a generalization of the class of nonexpansive mappings. They proved that if $K$ is a nonempty closed-convex bounded subset of a uniformly convex real Banach space and $T$ is an asymptotically nonexpansive self-mapping of $K$, then $T$ has a fixed point.

The class of mappings which are asymptotically nonexpansive in the intermediate sense was introduced by Bruck et al. [6]. It is known [7] that if $K$ is a nonempty closedconvex bounded subset of a uniformly convex Banach space $X$ and $T: K \rightarrow K$ is an asymptotically nonexpansive mapping in the intermediate sense, then $T$ has a fixed point. It is worth mentioning that the class of mappings which are asymptotically nonexpansive in the intermediate sense contains properly the class of asymptotically nonexpansive mappings (see, e.g., [8]).

The iterative approximation problems for nonexpansive mapping, asymptotically nonexpansive mapping, and asymptotically nonexpansive mapping in the intermediate sense were studied extensively in [5-20].

There are many different types of concepts which generalize a notion of nonexpansive mapping. One of such concepts is a total asymptotically nonexpansive mapping [21], and second one is an asymptotically I-nonexpansive mapping [22]. Let us recall some notions.

Definition 1.3. Let $K$ be a nonempty closed subset of a real normed linear space X.T $: K \rightarrow K$ is called a total asymptotically nonexpansive mapping if there exist nonnegative real sequence $\left\{\mu_{n}\right\}$ and $\left\{\lambda_{n}\right\}$ with $\mu_{n}, \lambda_{n} \rightarrow 0$ as $n \rightarrow \infty$ and strictly increasing continuous function $\phi: \mathbb{R}^{+} \rightarrow \mathbb{R}^{+}$with $\phi(0)=0$ such that for all $x, y \in K$,

$$
\left\|T^{n} x-T^{n} y\right\| \leq\|x-y\|+\mu_{n} \phi(\|x-y\|)+\lambda_{n}, \quad n \geq 1
$$


Remark 1.4. If $\phi(\xi)=\xi$, then (1.4) reduces to

$$
\left\|T^{n} x-T^{n} y\right\| \leq\left(1+\mu_{n}\right)\|x-y\|+\lambda_{n}, \quad n \geq 1 .
$$

In addition, if $\lambda_{n}=0$ for all $n \geq 1$, then total asymptotical nonexpansive mappings coincide with asymptotically nonexpansive mappings. If $\mu_{n}=0$ and $\lambda_{n}=0$ for all $n \geq 1$, we obtain from (1.5) the class of mappings that includes the class of nonexpansive mappings. If $\mu_{n}=0$ and $\lambda_{n}=\sigma_{n}=\max \left\{0, a_{n}\right\}$, where $a_{n}:=\sup _{x, y \in K}\left(\left\|T^{n} x-T^{n} y\right\|-\|x-y\|\right)$ for all $n \geq 1$, then (1.5) reduces to (1.3) which has been studied as mappings asymptotically nonexpansive in the intermediate sense.

The idea of the definition of a total asymptotically nonexpansive mappings is to unify various definitions of classes of mappings associated with the class of asymptotically nonexpansive mappings and to prove a general convergence theorems applicable to all these classes of nonlinear mappings.

Alber et al. [21] studied methods of approximation of fixed points of total asymptotically nonexpansive mappings. C. E. Chidume and E. U. Ofoedu [23] introduced an iterative scheme for approximation of a common fixed point of a finite family of total asymptotically nonexpansive mappings in Banach spaces. Recently, C. E. Chidume and E. U. Ofoedu [24] constructed a new iterative sequence much simpler than other types of approximation of common fixed points of finite families of total asymptotically nonexpansive mappings.

On the other hand, in [22] an asymptotically I-nonexpansive mapping was introduced.

Definition 1.5. Let $T: K \rightarrow K, I: K \rightarrow K$ be two mappings of a nonempty subset $K$ of a real normed linear space $X$, then $T$ is said to be

(i) I-nonexpansive if $\|T x-T y\| \leq\|I x-I y\|$ for all $x, y \in K$,

(ii) asymptotically I-nonexpansive, if there exists a sequence $\left\{\lambda_{n}\right\} \subset[1, \infty)$ with $\lim _{n \rightarrow \infty} \lambda_{n}=1$ such that $\left\|T^{n} x-T^{n} y\right\| \leq \lambda_{n}\left\|I^{n} x-I^{n} y\right\|$ for all $x, y \in K$ and $n \geq 1$.

Best approximation properties of $I$-nonexpansive mappings were investigated in $[22,25]$. In [26], strong convergence of Mann iterations of I-nonexpansive mapping has been proved. In [27], the weak convergence of three-step Noor iterative scheme for an I-nonexpansive mapping in a Banach space has been established. In [28], the weakly convergence theorem for asymptotically $I$-nonexpansive mapping defined in Hilbert space was proved. Recently, in [29-31], the weak and strong convergence of explicit and implicit iteration process to a common fixed point of a finite family of asymptotically $I$-nonexpansive mappings have been studied.

In this paper, we introduce a new type of concept of a generalization of nonexpansive mapping's nation, which is a combination of Definitions 1.3 and 1.5.

Definition 1.6. Let $T: K \rightarrow K, I: K \rightarrow K$ be two mappings of a nonempty subset $K$ of a real normed linear space $X$, then $T$ is said to be a total asymptotically $I$-nonexpansive mapping 
if there exist nonnegative real sequences $\left\{\mu_{n}\right\}$ and $\left\{\lambda_{n}\right\}$ with $\mu_{n}, \lambda_{n} \rightarrow 0$ as $n \rightarrow \infty$ and the strictly increasing continuous function $\phi: \mathbb{R}^{+} \rightarrow \mathbb{R}^{+}$with $\phi(0)=0$ such that for all $x, y \in K$,

$$
\left\|T^{n} x-T^{n} y\right\| \leq\left\|I^{n} x-I^{n} y\right\|+\mu_{n} \phi\left(\left\|I^{n} x-I^{n} y\right\|\right)+\lambda_{n}, \quad n \geq 1
$$

Now let us provide an example of a total asymptotically I-nonexpansive mapping, which is not asymptotically nonexpansive mapping.

Example 1.7. Let us consider the space $\ell_{1}$, and let $B_{1}=\left\{\mathbf{x} \in \ell_{1}:\|\mathbf{x}\|_{1} \leq 1\right\}$. Define a nonlinear operator $T: \ell_{1} \rightarrow \ell_{1}$ by

$$
T_{\alpha}\left(x_{1}, x_{2}, \ldots, x_{n}, \ldots\right)=\left(0, \alpha \sqrt{\left|x_{1}\right|}, \alpha x_{2}, \ldots, \alpha x_{n}, \ldots\right), \quad \alpha \in(0,1)
$$

Let $\|\mathbf{x}\|_{1} \leq 1$, then from

$$
\begin{aligned}
\left\|T_{\alpha}(\mathbf{x})\right\|_{1} & =\alpha\left(\|\mathbf{x}\|_{1}-\left|x_{1}\right|+\sqrt{\left|x_{1}\right|}\right) \\
& \leq \alpha\left(1-\left|x_{1}\right|+\sqrt{\left|x_{1}\right|}\right) \leq 1,
\end{aligned}
$$

one gets $T\left(B_{1}\right) \subset B_{1}$.

One can find that

$$
T_{\alpha}^{k}\left(x_{1}, x_{2}, \ldots, x_{n}, \ldots\right)=(\underbrace{0, \ldots, 0}_{k}, \alpha^{k} \sqrt{\left|x_{1}\right|}, \alpha^{k} x_{2}, \ldots, \alpha^{k} x_{n}, \ldots) .
$$

Hence,

$$
\left\|T_{\alpha}^{k}(\mathbf{x})-T_{\alpha}^{k}(\mathbf{y})\right\|_{1}=\alpha^{k}\left(\|\mathbf{x}-\mathbf{y}\|_{1}+\left|\sqrt{\left|x_{1}\right|}-\sqrt{\left|y_{1}\right|}\right|-\left|x_{1}-y_{1}\right|\right) .
$$

From $\mathbf{x}, \mathbf{y} \in B_{1}$, we have

$$
\left|\sqrt{\left|x_{1}\right|}-\sqrt{\left|y_{1}\right|}\right| \leq \sqrt{|| x_{1}|-| y_{1}||} \leq \sqrt{\|x-y\|_{1}} .
$$

So, it follows from (1.10) and (1.11) that

$$
\left\|T_{\alpha}^{k}(\mathbf{x})-T_{\alpha}^{k}(\mathbf{y})\right\|_{1} \leq \alpha^{k}\left(\|\mathbf{x}-\mathbf{y}\|_{1}+\sqrt{\|\mathbf{x}-\mathbf{y}\|_{1}}\right) \quad \forall \mathbf{x}, \mathbf{y} \in B_{1}, k \in \mathbb{N} .
$$


Now consider a new Banach space $\mathbb{R} \times \ell_{1}$ with a norm $\|\mathbb{X}\|=|x|+\|\mathbf{x}\|_{1}$, where $\mathbb{X}=(x, \mathbf{x})$ and define a new mapping $S: \mathbb{R} \times \ell_{1} \rightarrow \mathbb{R} \times \ell_{1}$ by

$$
S(x, \mathbf{x})=\left(x, T_{\alpha}(\mathbf{x})\right)
$$

Let $K=[0,1] \times B_{1}$, then it is clear that $S(K) \subset K$. One can see that $S^{k}(x, \mathbf{x})=\left(x, T_{\alpha}^{k}(\mathbf{x})\right)$. Therefore, using (1.14), we obtain

$$
\begin{aligned}
\left\|S^{k}(\mathbb{X})-S^{k}(\mathbb{Y})\right\| & =|x-y|+\left\|T_{\alpha}^{k}(\mathbf{x})-T_{\alpha}^{k}(\mathbf{y})\right\|_{1} \\
& \leq|x-y|+\alpha^{k}\left(\|\mathbf{x}-\mathbf{y}\|_{1}+\sqrt{\|\mathbf{x}-\mathbf{y}\|_{1}}\right) \\
& \leq\|\mathbb{X}-\mathbb{Y}\|+\alpha^{k}(\|\mathbb{X}-\mathbb{Y}\|+\sqrt{\|\mathbb{X}-\mathbb{Y}\|})
\end{aligned}
$$

We let $\phi(t)=t+\sqrt{t}$ and $\mu_{k}=\alpha^{k}$. It is clear that $\phi(0)=0$ and $\phi$ is strictly increasing, and moreover, (1.14) implies

$$
\left\|S^{k}(\mathbb{X})-S^{k}(\mathbb{X})\right\| \leq\|I \mathbb{X}-I \mathbb{Y}\|+\mu_{k} \phi(\|I \mathbb{X}-I \mathbb{Y}\|),
$$

that is $S$ is a totally asymptotically $I$-nonexpansive mapping. Here, $I$ is the identity mapping of $\mathbb{R} \times \ell_{1}$.

Now we are going to show that $S$ is not asymptotically nonexpansive. Namely, we will establish that for any sequence of positive numbers $\left\{\lambda_{n}\right\}$ with $\lambda_{n} \rightarrow 0$ and any $k \in \mathbb{N}$, one can find $\mathbb{X}_{0}, \mathbb{Y}_{0}$ such that

$$
\left\|S^{k}\left(\mathbb{X}_{0}\right)-S^{k}\left(\mathbb{Y}_{0}\right)\right\|>\left(1+\lambda_{k}\right)\left\|\mathbb{X}_{0}-\mathbb{Y}_{0}\right\|
$$

In fact, choose $\mathbb{X}_{0}, \mathbb{Y}_{0}$ as follows:

$$
\mathbb{X}_{0}=\left(0, \mathbf{x}_{0}\right), \quad \mathbb{Y}_{0}=\left(0, \mathbf{y}_{0}\right),
$$

where

$$
\begin{gathered}
\mathbf{x}_{0}=\left(x_{0}, 0, \ldots, 0, \ldots\right), \quad \mathbf{y}_{0}=\left(\frac{x_{0}}{4}, 0, \ldots, 0, \ldots\right), \\
0<x_{0}<\frac{4 \alpha^{2 k}}{9\left(1+\lambda_{k}\right)^{2}}
\end{gathered}
$$

From (1.10), one finds that

$$
\begin{gathered}
\left\|S^{k}\left(\mathbb{X}_{0}\right)-S^{k}\left(\mathbb{Y}_{0}\right)\right\|=\alpha^{k}\left|\sqrt{x_{0}}-\frac{\sqrt{x_{0}}}{2}\right|=\alpha^{k} \frac{\sqrt{x_{0}}}{2}, \\
\left\|\mathbb{X}_{0}-\mathbb{Y}_{0}\right\|=\frac{3 x_{0}}{4} .
\end{gathered}
$$


The last equalities with (1.18) imply that

$$
\frac{\left\|S^{k}\left(\mathbb{X}_{0}\right)-S^{k}\left(\mathbb{Y}_{0}\right)\right\|}{\left\|\mathbb{X}_{0}-\mathbb{Y}_{0}\right\|}=\frac{2 \alpha^{k}}{3 \sqrt{x_{0}}}>1+\lambda_{k}
$$

This yields the required assertion. Note that $S$ has infinitely many fixed points in $K$, that is, $\operatorname{Fix}(S)=\{(x, 0): x \in[0,1]\}$.

Example 1.8. Let us consider the Banach space $\mathbb{R} \times \ell_{1}$ defined as before, and let $f$ be a mapping of a segment $C \subset \mathbb{R}$ to itself, that is, $f: C \rightarrow C$ with $f(0)=0$ and

$$
\left|f^{n}(x)-f^{n}(y)\right| \leq|x-y|+c_{n}, \quad c_{n}>0, n \in \mathbb{N}
$$

where $c_{n} \rightarrow 0$. Note that such kind of functions do exist. One can take (see for more details [8]) $C=[-1 / \pi, 1 / \pi]$ and

$$
f_{\mathcal{K}}(x)=\left\{\begin{array}{cl}
\kappa x \sin \frac{1}{x}, & x \neq 0, \kappa \in(0,1) . \\
0, & x=0 .
\end{array}\right.
$$

Define a new mapping $S_{f}: C \times B_{1} \rightarrow C \times B_{1}$ by

$$
S_{f}(x, \mathbf{x})=\left(f(x), T_{\alpha}(\mathbf{x})\right)
$$

here $T$ is defined as above (see (1.7)). Using the same argument as the above Example 1.7, we can establish that

$$
\left\|S_{f}^{k}(\mathbb{X})-S_{f}^{k}(\mathbb{X})\right\| \leq\|\mathbb{X}-\mathbb{Y}\|+\mu_{k} \phi(\|\mathbb{X}-\mathbb{Y}\|)+c_{k} \quad \forall k \in \mathbb{N} .
$$

Moreover, such a mapping is not asymptotically nonexpansive. Note that the mapping $S_{f_{\kappa}}$ with the function $f_{\kappa}$ has a unique fixed point in $C \times B_{1}$.

Remark 1.9. To the best our knowledge, we should stress that the constructed examples are currently only unique examples of totaly asymptotically nonexpansive mappings which are not asymptotically nonexpansive. Before, no such examples were known in the literature.

The aim of the present paper is unification of all known iterative methods by introducing a new iterative scheme for approximation of common fixed points of finite families of total asymptotically I-nonexpansive mappings. Note that such a scheme contains a particular case of the method introduced in [24] and allows us to construct more simpler methods than $[23,24]$.

Namely, let $K$ be a nonempty closed-convex subset of a real Banach space $X$ and $\left\{T_{i}\right\}_{i=1}^{m}: K \rightarrow K$ be a finite family of total asymptotically $I_{i}$-nonexpansive mappings, that is,

$$
\left\|T_{i}^{n} x-T_{i}^{n} y\right\| \leq\left\|I_{i}^{n} x-I_{i}^{n} y\right\|+\mu_{i n} \phi_{i}\left(\left\|I_{i}^{n} x-I_{i}^{n} y\right\|\right)+\lambda_{i n}
$$


and $\left\{I_{i}\right\}_{i=1}^{m}: K \rightarrow K$ is a finite family of total asymptotically nonexpansive mappings, that is,

$$
\left\|I_{i}^{n} x-I_{i}^{n} y\right\| \leq\|x-y\|+\tilde{\mu}_{i n} \varphi_{i}(\|x-y\|)+\tilde{\lambda}_{i n}
$$

here $\phi_{i}, \varphi_{i}: \mathbb{R}^{+} \rightarrow \mathbb{R}^{+}$are the strictly increasing continuous functions with $\phi_{i}(0)=\varphi_{i}(0)=0$ for all $i=\overline{1, m}$, and $\left\{\mu_{i n}\right\}_{n=1}^{\infty},\left\{\lambda_{i n}\right\}_{n=1}^{\infty},\left\{\tilde{\mu}_{i n}\right\}_{n=1}^{\infty},\left\{\tilde{\lambda}_{i n}\right\}_{n=1}^{\infty}$ are nonnegative real sequences with $\mu_{i n}, \lambda_{i n}, \tilde{\mu}_{i n}, \tilde{\lambda}_{i n} \rightarrow 0$ as $n \rightarrow \infty$ for all $i=\overline{1, m}$. Then for given sequences $\left\{\alpha_{j n}\right\}_{n=1}^{\infty},\left\{\beta_{j n}\right\}_{n=1}^{\infty}$ in $(0,1)$, where $j=\overline{0, m}$, we will consider the following explicit iterative process:

$$
\begin{aligned}
x_{0} & \in K, \\
x_{n+1} & =\alpha_{0 n} x_{n}+\sum_{i=1}^{m} \alpha_{i n} T_{i}^{n} y_{n}, \\
y_{n} & =\beta_{0 n} x_{n}+\sum_{i=1}^{m} \beta_{i n} I_{i}^{n} x_{n},
\end{aligned}
$$

such that $\sum_{j=0}^{m} \alpha_{j n}=1$ and $\sum_{j=0}^{m} \beta_{j n}=1$.

C. E. Chidume and E. U. Ofoedu [24] have considered only a particular case of the explicit iterative process (1.27), in which $\left\{I_{i}\right\}_{i=1}^{m}$ is to be taken as the identity mappings. One of the main results of ([24], see Theorem 3.5, page 11) was correct, while the provided proof of that result was wrong. Since, in their proof, they used Lemma 2.3, but which actually is not applicable in that situation, the sequence $\left\{t_{n}\right\}_{n=1}^{\infty}$ tends to 0 . As a counterexample, we can consider the following one: let $x \in X,\|x\|=d>0$, and let the sequences $x_{n}, y_{n}$, and $t_{n}$ be defined as follows:

$$
x_{n}=x, \quad y_{n}=-x, \quad t_{n}=\frac{1}{n}, \quad \forall n \in \mathbb{N} .
$$

It is then clear that

$$
\lim _{n \rightarrow \infty}\left\|t_{n} x_{n}+\left(1-t_{n}\right) y_{n}\right\|=\|x\| \lim _{n \rightarrow \infty}\left|1-\frac{2}{n}\right|=d
$$

However,

$$
\lim _{n \rightarrow \infty}\left\|x_{n}-y_{n}\right\|=2 d>0
$$

In this paper, we shall provide a correct proof of Theorem 3.5 page 11 in [24]. As we already mentioned in Lemma 2.3 is not applicable the main result of [24]. Therefore, we first will generalize Lemma 2.3 to the case of finite number of sequences. Such a generalization gives us a possibility to prove the mentioned result. On other hand, the provided generalization presents an independent interest as well. Moreover, we extend and unify the main result of [24] for a finite family of total asymptotically $I_{i}$-nonexpansive mappings $\left\{T_{i}\right\}_{i=1}^{m}$. Namely, we shall prove the strong convergence of the explicit iterative process (1.27) to a common fixed point of the finite family of total asymptotically $I_{i^{-}}$ nonexpansive mappings $\left\{T_{i}\right\}_{i=1}^{m}$ and the finite family of total asymptotically nonexpansive 
mappings $\left\{I_{i}\right\}_{i=1}^{m}$. Here, we stress that Lemmas 3.1 and 3.2 play a crucial role. All presented results here extend, generalize, unify, and improve the corresponding main results of $[21,24,29-33]$.

\section{Preliminaries}

Throughout this paper, we always assume that $X$ is a real Banach space. The following lemmas play an important role in proving our main results.

Lemma 2.1 (see [16]). Let $\left\{a_{n}\right\},\left\{b_{n}\right\}$, and $\left\{c_{n}\right\}$ be three sequences of nonnegative real numbers with $\sum_{n=1}^{\infty} b_{n}<\infty, \sum_{n=1}^{\infty} c_{n}<\infty$. If the following condition is satisfied:

(i) $a_{n+1} \leq\left(1+b_{n}\right) a_{n}+c_{n}, n \geq 1$,

then the $\operatorname{limit}_{\lim _{n \rightarrow \infty}} a_{n}$ exists.

Lemma 2.2 (see [34]). Let $X$ be a uniformly convex Banach space and $t \in(0,1)$. Suppose that $\left\{x_{n}\right\},\left\{y_{n}\right\}$ are two sequences in $X$ such that

$$
\lim _{n \rightarrow \infty}\left\|t x_{n}+(1-t) y_{n}\right\|=d, \quad \limsup _{n \rightarrow \infty}\left\|x_{n}\right\| \leq d, \quad \limsup _{n \rightarrow \infty}\left\|y_{n}\right\| \leq d
$$

hold some $d \geq 0$, then $\lim _{n \rightarrow \infty}\left\|x_{n}-y_{n}\right\|=0$.

Lemma 2.3 (see [14]). Let $X$ be a uniformly convex Banach space, and let $b, c$ be two constants with $0<b<c<1$. Suppose that $\left\{t_{n}\right\}$ is a sequence in $[b, c]$ and $\left\{x_{n}\right\},\left\{y_{n}\right\}$ are two sequences in $X$ such that

$$
\lim _{n \rightarrow \infty}\left\|t_{n} x_{n}+\left(1-t_{n}\right) y_{n}\right\|=d, \quad \limsup _{n \rightarrow \infty}\left\|x_{n}\right\| \leq d, \quad \limsup _{n \rightarrow \infty}\left\|y_{n}\right\| \leq d,
$$

hold some $d \geq 0$, then $\lim _{n \rightarrow \infty}\left\|x_{n}-y_{n}\right\|=0$.

\section{Main Results}

In this section, we shall prove our main results. To formulate ones, we need some auxiliary results.

First we are going to generalize Lemmas 2.2 and 2.3 for $m$ number of sequences $\left\{z_{i n}\right\}_{n=1}^{\infty}$ from the uniformly convex Banach space $X$, where $i=\overline{1, m}$.

Lemma 3.1. Let $X$ be a uniformly convex Banach space and $\alpha_{i} \in(0,1), i=\overline{1, m}$ any constants with $\sum_{i=1}^{m} \alpha_{i}=1$. Suppose that $\left\{z_{i n}\right\}_{n=1}^{\infty}, i=\overline{1, m}$ are sequences in $X$ such that

$$
\lim _{n \rightarrow \infty}\left\|\sum_{i=1}^{m} \alpha_{i} z_{i n}\right\|=d, \quad \limsup _{n \rightarrow \infty}\left\|z_{i n}\right\| \leq d, \quad \forall i=\overline{1, m}
$$

hold some $d \geq 0$, then $\lim _{n \rightarrow \infty} \lim \left\|z_{i n}\right\|=d$ and $\lim _{n \rightarrow \infty}\left\|z_{i n}-z_{j n}\right\|=0$ for any $i, j=\overline{1, m}$. 
Proof. Let us first prove $\lim _{n \rightarrow \infty}\left\|z_{i n}\right\|=d$ for any $i=\overline{1, m}$. Indeed, it follows from (3.1) that

$$
\begin{aligned}
d & =\lim _{n \rightarrow \infty}\left\|\sum_{k=1}^{m} \alpha_{k} z_{k n}\right\|=\liminf _{n \rightarrow \infty}\left\|\sum_{k=1}^{m} \alpha_{k} z_{k n}\right\| \\
& \leq \liminf _{n \rightarrow \infty}\left(\sum_{k=1}^{m} \alpha_{k}\left\|z_{k n}\right\|\right) \leq \alpha_{i} \liminf \left\|z_{i n}\right\|+\sum_{k \neq i} \alpha_{k} \limsup _{n \rightarrow \infty}\left\|z_{k n}\right\| \\
& \leq \alpha_{i} \liminf _{n \rightarrow \infty}\left\|z_{i n}\right\|+\left(1-\alpha_{i}\right) d .
\end{aligned}
$$

We then get that $\liminf _{n \rightarrow \infty}\left\|z_{i n}\right\| \geq d$, which means $\lim _{n \rightarrow \infty}\left\|z_{i n}\right\|=d$.

Now we prove the statement $\lim _{n \rightarrow \infty}\left\|z_{i n}-z_{j n}\right\|=0$ by means of mathematical induction with respect to $m$. For $m=2$, the statement immediately follows from Lemma 2.2. Assume that the statement is true, for $m=k-1$. Let us prove for $m=k$. To do this, denote

$$
t_{n}=\frac{1}{1-\alpha_{k}} \sum_{i=1}^{k-1} \alpha_{i} z_{i n}
$$

Since $\left(1 / 1-\alpha_{k}\right) \sum_{i=1}^{k-1} \alpha_{i}=1$, we get $\limsup _{n \rightarrow \infty}\left\|t_{n}\right\| \leq d$. On the other hand, one has

$$
\begin{aligned}
d & =\liminf _{n \rightarrow \infty}\left\|\sum_{i=1}^{k} \alpha_{i} z_{i n}\right\|=\liminf _{n \rightarrow \infty}\left\|\left(1-\alpha_{k}\right) t_{n}+\alpha_{k} z_{k n}\right\| \\
& \leq\left(1-\alpha_{k}\right) \liminf _{n \rightarrow \infty}\left\|t_{n}\right\|+\alpha_{k} \limsup _{n \rightarrow \infty}\left\|z_{k n}\right\| \\
& \leq\left(1-\alpha_{k}\right) \liminf _{n \rightarrow \infty}\left\|t_{n}\right\|+\alpha_{k} d .
\end{aligned}
$$

We then obtain $\liminf _{n \rightarrow \infty}\left\|t_{n}\right\| \geq d$ which means $\lim _{n \rightarrow \infty}\left\|t_{n}\right\|=d$. In this case, according to the assumption of induction with the sequence $t_{n}$, we can conclude that $\lim _{n \rightarrow \infty}\left\|z_{i n}-z_{j n}\right\|=0$, if $1 \leq i, j \leq k-1$.

Since $\lim _{n \rightarrow \infty}\left\|\left(1-\alpha_{k}\right) t_{n}+\alpha_{k} z_{k n}\right\|=d$ due to Lemma 2.2, one gets

$$
\lim _{n \rightarrow \infty}\left\|t_{n}-z_{k n}\right\|=0
$$

If $1 \leq j \leq k-1$, then the following inequality

$$
\begin{aligned}
\left\|z_{j n}-z_{k n}\right\| & \leq\left\|z_{j n}-t_{n}\right\|+\left\|t_{n}-z_{k n}\right\| \\
& \leq \frac{1}{1-\alpha_{k}} \sum_{i=1}^{k-1} \alpha_{i}\left\|z_{i n}-z_{j n}\right\|+\left\|t_{n}-z_{k n}\right\|
\end{aligned}
$$

implies that $\lim _{n \rightarrow \infty}\left\|z_{j n}-z_{k n}\right\|=0$. This completes the proof. 
Lemma 3.2. Let $X$ be a uniformly convex Banach space, and let $\alpha_{*}, \alpha^{*}$ be two constants with $0<$ $\alpha_{*}<\alpha^{*}<1$. Suppose that $\left\{\alpha_{i n}\right\}_{n=1}^{\infty} \subset\left[\alpha_{*}, \alpha^{*}\right], i=\overline{1, m}$ are any sequences with $\sum_{i=1}^{m} \alpha_{i n}=1$ for all $n \in \mathbb{N}$. Suppose that $\left\{z_{i n}\right\}_{n=1}^{\infty}, i=\overline{1, m}$ are sequences in $X$ such that

$$
\lim _{n \rightarrow \infty}\left\|\sum_{i=1}^{m} \alpha_{i n} z_{i n}\right\|=d, \quad \limsup _{n \rightarrow \infty}\left\|z_{i n}\right\| \leq d, \quad \forall i=\overline{1, m}
$$

hold for some $d \geq 0$, then $\lim _{n \rightarrow \infty}\left\|z_{i n}\right\|=d$ and $\lim _{n \rightarrow \infty}\left\|z_{i n}-z_{j n}\right\|=0$ for any $i, j=\overline{1, m}$.

Proof. Analogously as in the proof of Lemma 3.1, it is easy to show that $\lim _{n \rightarrow \infty}\left\|z_{i n}\right\|=d$. Therefore, let us prove the statement $\lim _{n \rightarrow \infty}\left\|z_{i n}-z_{j n}\right\|=0$ for any $i, j=\overline{1, m}$. Suppose to the contrary, that there exist two numbers $i_{0}, j_{0}$ such that

$$
\limsup _{n \rightarrow \infty}\left\|z_{i_{0} n}-z_{j_{0} n}\right\|=\beta_{i_{0}, j_{0}}>0
$$

then there exists a subsequence $\left\{z_{i_{0} n_{k}}-z_{j_{0} n_{k}}\right\}_{k=1}^{\infty}$ of $\left\{z_{i_{0} n}-z_{j_{0} n}\right\}_{n=1}^{\infty}$ such that $\lim _{k \rightarrow \infty} \| z_{i_{0} n_{k}}-$ $z_{j_{0} n_{k}} \|=\beta_{i_{0} j_{0}}$.

Let us consider the subsequences $\left\{\alpha_{i n_{k}}\right\}_{k=1}^{\infty}$ of $\left\{\alpha_{i n}\right\}_{n=1}^{\infty}$, here $i=\overline{1, m}$. Since $\left\{\alpha_{i n_{k}}\right\}_{k=1}^{\infty} \subset$ $\left[\alpha_{*}, \alpha^{*}\right]$, there exists a subsequence $\left\{n_{k_{l}}\right\}_{l=1}^{\infty}$ of $\left\{n_{k}\right\}_{k=1}^{\infty}$ such that $\lim _{l \rightarrow \infty} \alpha_{i n_{k_{l}}}=\alpha_{i}$ for all $i=\overline{1, m}$. Since $\sum_{i=1}^{m} \alpha_{i n}=1$, for all $n \in \mathbb{N}$, one gets $\sum_{i=1}^{m} \alpha_{i}=1$, and $\alpha_{i} \in\left[\alpha_{*}, \alpha^{*}\right]$, for all $i=\overline{1, m}$. We know that

$$
\begin{aligned}
d & =\lim _{l \rightarrow \infty}\left\|\sum_{i=1}^{m} \alpha_{i n_{k_{l}}} z_{i n_{k_{l}}}\right\|=\liminf _{l \rightarrow \infty}\left\|\sum_{i=1}^{m}\left(\left(\alpha_{i n_{k_{l}}}-\alpha_{i}\right) z_{i n_{k_{l}}}+\alpha_{i} z_{i n_{k_{l}}}\right)\right\| \\
& \leq \liminf _{l \rightarrow \infty}\left(\sum_{i=1}^{m}\left|\alpha_{i n_{k_{l}}}-\alpha_{i}\right|\left\|z_{i n_{k_{l}}}\right\|+\left\|\sum_{i=1}^{m} \alpha_{i} z_{i n_{k_{l}}}\right\|\right) \\
& \leq \sum_{i=1}^{m} \limsup _{l \rightarrow \infty}\left(\left|\alpha_{i n_{k_{l}}}-\alpha_{i}\right|\left\|z_{i n_{k_{l}}}\right\|\right)+\liminf _{l \rightarrow \infty}\left\|\sum_{i=1}^{m} \alpha_{i} z_{i n_{k_{l}}}\right\| .
\end{aligned}
$$

It then follows that $\liminf _{l \rightarrow \infty}\left\|\sum_{i=1}^{m} \alpha_{i} z_{i n_{k_{l}}}\right\| \geq d$. On the other hand, we have

$$
\underset{l \rightarrow \infty}{\limsup }\left\|\sum_{i=1}^{m} \alpha_{i} z_{i n_{k_{l}}}\right\| \leq \sum_{i=1}^{m} \alpha_{i} \limsup _{l \rightarrow \infty}\left\|z_{i n_{k_{l}}}\right\| \leq d
$$

Therefore, $\lim _{l \rightarrow \infty}\left\|\sum_{i=1}^{m} \alpha_{i} z_{i n_{k_{l}}}\right\|=d$. Consequently, Lemma 3.1 implies that $\lim _{l \rightarrow \infty} \| z_{i_{0} n_{k_{l}}}-$ $z_{j_{0} n_{k_{l}}} \|=0$. However, it contradicts to

$$
\lim _{l \rightarrow \infty}\left\|z_{i_{0} n_{k_{l}}}-z_{j_{0} n_{k_{l}}}\right\|=\lim _{k \rightarrow \infty}\left\|z_{i_{0} n_{k}}-z_{j_{0} n_{k}}\right\|=\beta_{i_{0} j_{0}}>0
$$

This completes the proof. 
Proposition 3.3. Let $X$ be a real Banach space, and let $K$ be a nonempty closed-convex subset of $X$. Let $\left\{T_{i}\right\}_{i=1}^{m}: K \rightarrow K$ be a finite family of total asymptotically $I_{i}$-nonexpansive mappings with sequences $\left\{\mu_{i n}\right\}_{n=1}^{\infty},\left\{\lambda_{i n}\right\}_{n=1}^{\infty}$, where $i=\overline{1, m}$, and let $\left\{I_{i}\right\}_{i=1}^{m}: K \rightarrow K$ be a finite family of total asymptotically nonexpansive mappings with sequences $\left\{\tilde{\mu}_{i n}\right\}_{n=1}^{\infty},\left\{\tilde{\lambda}_{i n}\right\}_{n=1}^{\infty}$, where $i=\overline{1, m}$. Suppose that there exist $M_{i}, M_{i}^{*}, N_{i}, N_{i}^{*}>0, i=\overline{1, m}$ such that $\phi_{i}\left(\xi_{i}\right) \leq M_{i}^{*} \xi_{i}$, for all $\xi_{i} \geq M_{i}$ and $\varphi_{i}\left(\zeta_{i}\right) \leq N_{i}^{*} \zeta_{i}$ for all $\zeta_{i} \geq N_{i}$, where $i=\overline{1, m}$, then the following holds for any $x, y \in K$ and for any $i=\overline{1, m}$ :

$$
\begin{aligned}
\left\|I_{i}^{n} x-I_{i}^{n} y\right\| \leq & \left(1+\tilde{\mu}_{i n} N_{i}^{*}\right)\|x-y\|+\tilde{\mu}_{i n} \varphi_{i}\left(N_{i}\right)+\tilde{\lambda}_{i n} \\
\left\|T_{i}^{n} x-T_{i}^{n} y\right\| \leq & \left(1+\mu_{i n} M_{i}^{*}\right)\left(1+\tilde{\mu}_{i n} N_{i}^{*}\right)\|x-y\|+\tilde{\mu}_{i n}\left(1+\mu_{i n} M_{i}^{*}\right) \varphi_{i}\left(N_{i}\right) \\
& +\tilde{\lambda}_{i n}\left(1+\mu_{i n} M_{i}^{*}\right)+\mu_{i n} \phi_{i}\left(M_{i}\right)+\lambda_{i n} .
\end{aligned}
$$

Proof. Since $\phi_{i}, \varphi_{i}: \mathbb{R}^{+} \rightarrow \mathbb{R}^{+}$are the strictly increasing continuous functions, where $i=\overline{1, m}$, it follows that $\phi_{i}\left(\xi_{i}\right) \leq \phi_{i}\left(M_{i}\right)$ and $\varphi_{i}\left(\zeta_{i}\right) \leq \phi_{i}\left(N_{i}\right)$ whenever $\xi_{i} \leq M_{i}$ and $\zeta_{i} \leq N_{i}$, where $i=\overline{1, m}$. By the hypothesis of Proposition 3.3, for all $\xi_{i}, \zeta_{i} \geq 0$ and $i=\overline{1, m}$, we then get

$$
\begin{gathered}
\phi_{i}\left(\xi_{i}\right) \leq \phi_{i}\left(M_{i}\right)+M_{i}^{*} \zeta_{i} \\
\varphi_{i}\left(\zeta_{i}\right) \leq \varphi_{i}\left(N_{i}\right)+N_{i}^{*} \zeta_{i} .
\end{gathered}
$$

Since $\left\{T_{i}\right\}_{i=1}^{m}: K \rightarrow K,\left\{I_{i}\right\}_{i=1}^{m}: K \rightarrow K$ are total asymptotically $I_{i}$-nonexpansive and total asymptotically nonexpansive mappings, respectively, from (3.14) and (3.15), one gets

$$
\begin{aligned}
\left\|I_{i}^{n} x-I_{i}^{n} y\right\| \leq & \|x-y\|+\tilde{\mu}_{i n} \varphi_{i}(\|x-y\|)+\tilde{\lambda}_{i n} \\
\leq & \|x-y\|+\tilde{\mu}_{i n}\left(\varphi_{i}\left(N_{i}\right)+N_{i}^{*}\|x-y\|\right)+\tilde{\lambda}_{i n} \\
& =\left(1+\tilde{\mu}_{i n} N_{i}^{*}\right)\|x-y\|+\tilde{\mu}_{i n} \varphi_{i}\left(N_{i}\right)+\tilde{\lambda}_{i n}, \\
\left\|T_{i}^{n} x-T_{i}^{n} y\right\| \leq & \left\|I_{i}^{n} x-I_{i}^{n} y\right\|+\mu_{i n} \phi_{i}\left(\left\|I_{i}^{n} x-I_{i}^{n} y\right\|\right)+\lambda_{i n} \\
\leq & \left\|I_{i}^{n} x-I_{i}^{n} y\right\|+\mu_{i n}\left(\phi_{i}\left(M_{i}\right)+M_{i}^{*}\left\|I_{i}^{n} x-I_{i}^{n} y\right\|\right)+\lambda_{i n} \\
& =\left(1+\mu_{i n} M_{i}^{*}\right)\left\|I_{i}^{n} x-I_{i}^{n} y\right\|+\mu_{i n} \phi_{i}\left(M_{i}\right)+\lambda_{i n} \\
& \leq\left(1+\mu_{i n} M_{i}^{*}\right)\left(1+\tilde{\mu}_{i n} N_{i}^{*}\right)\|x-y\|+\tilde{\mu}_{i n}\left(1+\mu_{i n} M_{i}^{*}\right) \varphi_{i}\left(N_{i}\right) \\
& +\tilde{\lambda}_{i n}\left(1+\mu_{i n} M_{i}^{*}\right)+\mu_{i n} \phi_{i}\left(M_{i}\right)+\lambda_{i n} .
\end{aligned}
$$

Lemma 3.4. Let $X$ be a uniformly convex real Banach space, and let $K$ be a nonempty closed-convex subset of $X$. Let $\left\{T_{i}\right\}_{i=1}^{m}: K \rightarrow K$ be a finite family of total asymptotically $I_{i}$-nonexpansive mappings with sequences $\left\{\mu_{i n}\right\}_{n=1}^{\infty},\left\{\lambda_{i n}\right\}_{n=1}^{\infty}$, where $i=\overline{1, m}$, and let $\left\{I_{i}\right\}_{i=1}^{m}: K \rightarrow K$ be a finite family of total asymptotically nonexpansive mappings with sequences $\left\{\tilde{\mu}_{i n}\right\}_{n=1}^{\infty},\left\{\tilde{\lambda}_{i n}\right\}_{n=1}^{\infty}$, where $i=\overline{1, m}$, such that $F:=\bigcap_{i=1}^{m}\left(F\left(T_{i}\right) \cap F\left(I_{i}\right)\right) \neq \emptyset$. Suppose that $\sum_{n=1}^{\infty} \mu_{i n}<\infty, \sum_{n=1}^{\infty} \lambda_{i n}<\infty, \sum_{n=1}^{\infty} \tilde{\mu}_{i n}<\infty$, 
$\sum_{n=1}^{\infty} \tilde{\lambda}_{i n}<\infty$ for all $i=\overline{1, m}$, and there exist $M_{i}, M_{i}^{*}, N_{i}, N_{i}^{*}>0, i=\overline{1, m}$ such that $\phi_{i}\left(\xi_{i}\right) \leq M_{i}^{*} \xi_{i}$, for all $\xi_{i} \geq M_{i}$ and $\varphi_{i}\left(\zeta_{i}\right) \leq N_{i}^{*} \zeta_{i}$ for all $\zeta_{i} \geq N_{i}$, where $i=\overline{1, m}$. If $\left\{x_{n}\right\}$ is the explicit iterative sequence defined by (1.27), then for each $p \in F$, the limit $\lim _{n \rightarrow \infty}\left\|x_{n}-p\right\|$ exists.

Proof. Since $F \neq \emptyset$, for any given $p \in F$, it follows from (1.27) and (3.13) that

$$
\begin{aligned}
\left\|x_{n+1}-p\right\|= & \left\|\left(1-\sum_{i=1}^{m} \alpha_{i n}\right)\left(x_{n}-p\right)+\sum_{i=1}^{m} \alpha_{i n}\left(T_{i}^{n} y_{n}-p\right)\right\| \\
\leq & \left(1-\sum_{i=1}^{m} \alpha_{i n}\right)\left\|x_{n}-p\right\|+\sum_{i=1}^{m} \alpha_{i n}\left\|T_{i}^{n} y_{n}-p\right\| \\
\leq & \left(1-\sum_{i=1}^{m} \alpha_{i n}\right)\left\|x_{n}-p\right\| \\
& +\sum_{i=1}^{m} \alpha_{i n}\left(1+\mu_{i n} M_{i}^{*}\right)\left(1+\tilde{\mu}_{i n} N_{i}^{*}\right)\left\|y_{n}-p\right\| \\
& +\sum_{i=1}^{m}\left(\alpha_{i n} \tilde{\mu}_{i n}\left(1+\mu_{i n} M_{i}^{*}\right) \varphi_{i}\left(N_{i}\right)+\alpha_{i n} \tilde{\lambda}_{i n}\left(1+\mu_{i n} M_{i}^{*}\right)\right) \\
& +\sum_{i=1}^{m}\left(\alpha_{i n} \mu_{i n} \phi_{i}\left(M_{i}\right)+\alpha_{i n} \lambda_{i n}\right) .
\end{aligned}
$$

Again from (1.27) and (3.12), we derive that

$$
\begin{aligned}
\left\|y_{n}-p\right\|= & \left\|\left(1-\sum_{i=1}^{m} \beta_{i n}\right)\left(x_{n}-p\right)+\sum_{i=1}^{m} \beta_{i n}\left(I_{i}^{n} x_{n}-p\right)\right\| \\
\leq & \left(1-\sum_{i=1}^{m} \beta_{i n}\right)\left\|x_{n}-p\right\|+\sum_{i=1}^{m} \beta_{i n}\left\|I_{i}^{n} x_{n}-p\right\| \\
= & \left(1+\sum_{i=1}^{m} \tilde{\mu}_{i n} \beta_{i n} N_{i}^{*}\right)\left\|x_{n}-p\right\| \\
& +\sum_{i=1}^{m}\left(\tilde{\mu}_{i n} \beta_{i n} \varphi_{i}\left(N_{i}\right)+\tilde{\lambda}_{i n} \beta_{i n}\right) .
\end{aligned}
$$

Then from (3.17) and (3.18), one finds

$$
\left\|x_{n+1}-p\right\| \leq\left(1+b_{n}\right)\left\|x_{n}-p\right\|+c_{n} .
$$


Here

$$
\begin{aligned}
b_{n}= & \sum_{i=1}^{m}\left(\mu_{i n} \alpha_{i n} M_{i}^{*}+\tilde{\mu}_{i n} \alpha_{i n} N_{i}^{*}+\alpha_{i n} \sum_{i=1}^{m} \tilde{\mu}_{i n} \beta_{i n} N_{i}^{*}\right) \\
& +\sum_{i=1}^{m} \mu_{i n} \tilde{\mu}_{i n} \alpha_{i n} M_{i}^{*} N_{i}^{*}+\sum_{i=1}^{m} \mu_{i n} \alpha_{i n} M_{i}^{*} \cdot \sum_{i=1}^{m} \tilde{\mu}_{i n} \beta_{i n} N_{i}^{*} \\
& +\sum_{i=1}^{m} \tilde{\mu}_{i n} \alpha_{i n} N_{i}^{*} \cdot \sum_{i=1}^{m} \tilde{\mu}_{i n} \beta_{i n} N_{i}^{*} \\
c_{n}= & \sum_{i=1}^{m}\left(\tilde{\mu}_{i n} \beta_{i n} \varphi_{i}\left(N_{i}\right)+\tilde{\lambda}_{i n} \beta_{i n}\right) \cdot \sum_{i=1}^{m} \alpha_{i n}\left(1+\mu_{i n} M_{i}^{*}\right)\left(1+\tilde{\mu}_{i n} N_{i}^{*}\right) \\
& +\sum_{i=1}^{m}\left(\tilde{\mu}_{i n} \alpha_{i n}\left(1+\mu_{i n} M_{i}^{*}\right) \varphi_{i}\left(N_{i}\right)+\tilde{\lambda}_{i n} \alpha_{i n}\left(1+\mu_{i n} M_{i}^{*}\right)\right) \\
& +\sum_{i=1}^{m}\left(\mu_{i n} \alpha_{i n} \phi_{i}\left(M_{i}\right)+\lambda_{i n} \alpha_{i n}\right) .
\end{aligned}
$$

Denoting $a_{n}=\left\|x_{n}-p\right\|$ in (3.19), one gets

$$
a_{n+1} \leq\left(1+b_{n}\right) a_{n}+c_{n}
$$

Since $\sum_{n=1}^{\infty} b_{n}<\infty$ and $\sum_{n=1}^{\infty} c_{n}<\infty$, it follows from Lemma 2.1 the existence of the limit $\lim _{n \rightarrow \infty} a_{n}$. This means the limit

$$
\lim _{n \rightarrow \infty}\left\|x_{n}-p\right\|=d
$$

exists, where $d \geq 0$ is a constant. This completes the proof.

Now we prove the following result.

Theorem 3.5. Let $X$ be a uniformly convex real Banach space, and let $K$ be a nonempty closed-convex subset of $X$. Let $\left\{T_{i}\right\}_{i=1}^{m}: K \rightarrow K$ be a finite family of total asymptotically $I_{i}$-nonexpansive continuous mappings with sequences $\left\{\mu_{i n}\right\}_{n=1}^{\infty},\left\{\lambda_{i n}\right\}_{n=1}^{\infty}$, where $i=\overline{1, m}$, and let $\left\{I_{i}\right\}_{i=1}^{m}: K \rightarrow K$ be a finite family of total asymptotically nonexpansive continuous mappings with sequences $\left\{\tilde{\mu}_{i n}\right\}_{n=1}^{\infty},\left\{\tilde{\lambda}_{i n}\right\}_{n=1}^{\infty}$, where $i=\overline{1, m}$, such that $F:=\bigcap_{i=1}^{m}\left(F\left(T_{i}\right) \cap F\left(I_{i}\right)\right) \neq \emptyset$. Suppose that $\sum_{n=1}^{\infty} \mu_{i n}<\infty, \sum_{n=1}^{\infty} \lambda_{i n}<\infty$, $\sum_{n=1}^{\infty} \tilde{\mu}_{i n}<\infty, \sum_{n=1}^{\infty} \tilde{\lambda}_{i n}<\infty$ for all $i=\overline{1, m}$, and there exist $M_{i}, M_{i}^{*}, N_{i}, N_{i}^{*}>0, i=\overline{1, m}$ such that $\phi_{i}\left(\xi_{i}\right) \leq M_{i}^{*} \xi_{i}$, for all $\xi_{i} \geq M_{i}$ and $\varphi_{i}\left(\zeta_{i}\right) \leq N_{i}^{*} \zeta_{i}$ for all $\zeta_{i} \geq N_{i}$, where $i=\overline{1, m}$, then the explicit iterative sequence $\left\{x_{n}\right\}$ defined by (1.27) converges strongly to a common fixed point in $F$ if and only if

$$
\liminf _{n \rightarrow \infty} d\left(x_{n}, F\right)=0
$$

Proof. The necessity of condition (3.23) is obvious. Let us prove the sufficiency part of the theorem. 
Since $\left\{T_{i}\right\}_{i=1}^{m},\left\{I_{i}\right\}_{i=1}^{m}: K \rightarrow K$ are continuous mappings, the sets $F\left(T_{i}\right)$ and $F\left(I_{i}\right)$ are closed. Hence, $F=\bigcap_{i=1}^{m}\left(F\left(T_{i}\right) \cap F\left(I_{i}\right)\right)$ is a nonempty closed set.

For any given $p \in F$, we have (see (3.19))

$$
\left\|x_{n+1}-p\right\| \leq\left(1+b_{n}\right)\left\|x_{n}-p\right\|+c_{n} .
$$

Hence, one finds

$$
d\left(x_{n+1}, F\right) \leq\left(1+b_{n}\right) d\left(x_{n}, F\right)+c_{n}
$$

From (3.25) due to Lemma 2.1, we obtain the existence of the $\operatorname{limit}_{n \rightarrow \infty} d\left(x_{n}, F\right)$. By condition (3.23), one gets

$$
\lim _{n \rightarrow \infty} d\left(x_{n}, F\right)=\liminf _{n \rightarrow \infty} d\left(x_{n}, F\right)=0 .
$$

Let us prove that the sequence $\left\{x_{n}\right\}$ converges strongly to a common fixed point in $F$. We first show that $\left\{x_{n}\right\}$ is Cauchy sequence in $X$. In fact, due to $1+t \leq \exp (t)$ for all $t>0$, and from (3.24), we obtain

$$
\left\|x_{n+1}-p\right\| \leq \exp \left(b_{n}\right)\left(\left\|x_{n}-p\right\|+c_{n}\right)
$$

Thus, for any positive integers $m, n$, from (3.27) with $\sum_{n=1}^{\infty} b_{n}<\infty, \sum_{n=1}^{\infty} c_{n}<\infty$, we find

$$
\begin{aligned}
\left\|x_{n+m}-p\right\| & \leq \exp \left(b_{n+m-1}\right)\left(\left\|x_{n+m-1}-p\right\|+c_{n+m-1}\right) \\
& \leq \exp \left(b_{n+m-1}+b_{n+m-2}\right)\left(\left\|x_{n+m-2}-p\right\|+c_{n+m-1}+c_{n+m-2}\right) \\
& \leq \cdots \leq \exp \left(\sum_{i=n}^{n+m-1} b_{i}\right)\left(\left\|x_{n}-p\right\|+\sum_{i=n}^{n+m-1} c_{i}\right) \\
& \leq \exp \left(\sum_{i=n}^{\infty} b_{i}\right)\left(\left\|x_{n}-p\right\|+\sum_{i=n}^{\infty} c_{i}\right) .
\end{aligned}
$$

Therefore, we get

$$
\begin{aligned}
\left\|x_{n+m}-x_{n}\right\| & \leq\left\|x_{n+m}-p\right\|+\left\|x_{n}-p\right\| \\
& \leq\left(1+\exp \left(\sum_{i=n}^{\infty} b_{i}\right)\right)\left\|x_{n}-p\right\|+\exp \left(\sum_{i=n}^{\infty} b_{i}\right) \sum_{i=n}^{\infty} c_{i} \\
& \leq W\left(\left\|x_{n}-p\right\|+\sum_{i=n}^{\infty} c_{i}\right),
\end{aligned}
$$

for all $p \in F$, where $0<W-1=\exp \left(\sum_{i=n}^{\infty} b_{i}\right)<\infty$. Taking infimum over $p \in F$ in (3.29) gives

$$
\left\|x_{n+m}-x_{n}\right\| \leq W\left(d\left(x_{n}, F\right)+\sum_{i=n}^{\infty} c_{i}\right) \text {. }
$$


Since $\lim _{n \rightarrow \infty} d\left(x_{n}, F\right)=0$ and $\sum_{i=1}^{\infty} c_{i}<\infty$, given $\varepsilon>0$, there exists an integer $N_{0}>0$ such that for all $n>N_{0}$, we have $d\left(x_{n}, F\right)<(\varepsilon / 2 W)$ and $\sum_{i=n}^{\infty} c_{i}<(\varepsilon / 2 W)$. Consequently, for all integers $n \geq N_{0}$ and $m \geq 1$ and from (3.30), we derive

$$
\left\|x_{n+m}-x_{n}\right\| \leq \varepsilon
$$

which means that $\left\{x_{n}\right\}$ is Cauchy sequence in $X$, and since $X$ is complete, there exists $x^{*} \in X$ such that the sequence $\left\{x_{n}\right\}$ converges strongly to $x^{*}$.

Now we show that $x^{*}$ is a common fixed point in $F$. Suppose for contradiction that $x^{*} \notin F$. Since $F$ is closed subset of $X$, we have that $d\left(x^{*}, F\right)>0$. However, for all $p \in F$, we have

$$
\left\|x^{*}-p\right\| \leq\left\|x_{n}-x^{*}\right\|+\left\|x_{n}-p\right\|
$$

This implies that

$$
d\left(x^{*}, F\right) \leq\left\|x_{n}-x^{*}\right\|+d\left(x_{n}, F\right),
$$

so that as $n \rightarrow \infty$ we obtain $d\left(x^{*}, F\right)=0$ which contradicts $d\left(x^{*}, F\right)>0$. Hence, $x^{*}$ is a common fixed point in $F$. This proves the required assertion.

To formulate and prove the main result, we need once more an auxiliary result.

Proposition 3.6. Let $X$ be a uniformly convex real Banach space, and let $K$ be a nonempty closedconvex subset of $X$. Let $\left\{T_{i}\right\}_{i=1}^{m}: K \rightarrow K$ be a finite family of total asymptotically $I_{i}$-nonexpansive continuous mappings with sequences $\left\{\mu_{i n}\right\}_{n=1}^{\infty},\left\{\lambda_{i n}\right\}_{n=1}^{\infty}$, where $i=\overline{1, m}$, and let $\left\{I_{i}\right\}_{i=1}^{m}: K \rightarrow K$ be a finite family of total asymptotically nonexpansive continuous mappings with sequences $\left\{\tilde{\mu}_{i n}\right\}_{n=1}^{\infty}$, $\left\{\tilde{\lambda}_{i n}\right\}_{n=1}^{\infty}$, where $i=\overline{1, m}$, such that $F:=\bigcap_{i=1}^{m}\left(F\left(T_{i}\right) \cap F\left(I_{i}\right)\right) \neq \emptyset$. Suppose that $\sum_{n=1}^{\infty} \mu_{i n}<\infty$, $\sum_{n=1}^{\infty} \lambda_{i n}<\infty, \sum_{n=1}^{\infty} \tilde{\mu}_{i n}<\infty, \sum_{n=1}^{\infty} \tilde{\lambda}_{i n}<\infty$ for all $i=\overline{1, m}$, and $\left\{\alpha_{j n}\right\}_{n=1}^{\infty},\left\{\beta_{j n}\right\}_{n=1}^{\infty}$ are sequences with $\left\{\alpha_{j n}\right\}_{n=1}^{\infty} \subset\left[\alpha_{*}, \alpha^{*}\right]$ and $\left\{\beta_{j n}\right\}_{n=1}^{\infty} \subset\left[\beta_{*}, \beta^{*}\right]$, for all $j=\overline{0, m}$, here $0<\alpha_{*}<\alpha^{*}<1,0<\beta_{*}<$ $\beta^{*}<1$, and there exist $M_{i}, M_{i}^{*}, N_{i}, N_{i}^{*}>0, i=\overline{1, m}$ such that $\phi_{i}\left(\xi_{i}\right) \leq M_{i}^{*} \xi_{i}$, for all $\xi_{i} \geq M_{i}$ and $\varphi_{i}\left(\zeta_{i}\right) \leq N_{i}^{*} \zeta_{i}$ for all $\zeta_{i} \geq N_{i}$, where $i=\overline{1, m}$. then the explicit iterative sequence $\left\{x_{n}\right\}$ defined by (1.27) satisfies the following:

$$
\begin{aligned}
& \lim _{n \rightarrow \infty}\left\|x_{n}-T_{i}^{n} x_{n}\right\|=0, \\
& \lim _{n \rightarrow \infty}\left\|x_{n}-I_{i}^{n} x_{n}\right\|=0,
\end{aligned}
$$

for all $i=\overline{1, m}$.

Proof. According to Lemma 3.4 for any $p \in F$, we have $\lim _{n \rightarrow \infty}\left\|x_{n}-p\right\|=d$. It follows from (1.27) that

$$
\left\|x_{n+1}-p\right\|=\left\|\alpha_{0 n}\left(x_{n}-p\right)+\sum_{i=1}^{m} \alpha_{i n}\left(T_{i}^{n} y_{n}-p\right)\right\| \longrightarrow d,
$$


as $n \rightarrow \infty$. By means of $\sum_{n=1}^{\infty} \mu_{i n}<\infty, \sum_{n=1}^{\infty} \lambda_{i n}<\infty, \sum_{n=1}^{\infty} \tilde{\mu}_{i n}<\infty, \sum_{n=1}^{\infty} \tilde{\lambda}_{\text {in }}<\infty$, for all $i=\overline{1, m}$, from (3.18), one yields that

$$
\begin{aligned}
\limsup _{n \rightarrow \infty}\left\|y_{n}-p\right\| \leq & \limsup _{n \rightarrow \infty}\left[\left(1+\sum_{i=1}^{m} \tilde{\mu}_{i n} \beta_{i n} N_{i}^{*}\right)\left\|x_{n}-p\right\|\right] \\
& +\limsup _{n \rightarrow \infty}\left[\sum_{i=1}^{m}\left(\tilde{\mu}_{i n} \beta_{i n} \varphi_{i}\left(N_{i}\right)+\tilde{\lambda}_{i n} \beta_{i n}\right)\right] \\
= & \limsup _{n \rightarrow \infty}\left\|x_{n}-p\right\|=d,
\end{aligned}
$$

and from (3.13), (3.37), we have

$$
\begin{aligned}
\limsup _{n \rightarrow \infty}\left\|T_{i}^{n} y_{n}-p\right\| \leq \limsup _{n \rightarrow \infty}[ & \left(1+\mu_{i n} M_{i}^{*}\right)\left(1+\tilde{\mu}_{i n} N_{i}^{*}\right)\left\|y_{n}-p\right\| \\
& \left.+\limsup _{n \rightarrow \infty} \tilde{\mu}_{i n}\left(1+\mu_{i n} M_{i}^{*}\right) \varphi_{i}\left(N_{i}\right)\right] \\
& +\limsup _{n \rightarrow \infty}\left[\widetilde{\lambda}_{i n}\left(1+\mu_{i n} M_{i}^{*}\right)+\mu_{i n} \phi_{i}\left(M_{i}\right)+\lambda_{i n}\right] \\
\leq & d,
\end{aligned}
$$

for all $i=\overline{1, m}$. Now using

$$
\limsup _{n \rightarrow \infty}\left\|x_{n}-p\right\|=d,
$$

with (3.38) and applying Lemma 3.2 to (3.36), one finds

$$
\lim _{n \rightarrow \infty}\left\|x_{n}-T_{i}^{n} y_{n}\right\|=0,
$$

for all $i=\overline{1, m}$. Now from (1.27) and (3.40), we infer that

$$
\lim _{n \rightarrow \infty}\left\|x_{n+1}-x_{n}\right\|=\lim _{n \rightarrow \infty}\left\|\sum_{i=1}^{m} \alpha_{i n}\left(T_{i}^{n} y_{n}-x_{n}\right)\right\|=0
$$

On the other hand, from (3.13), we have

$$
\begin{aligned}
\left\|x_{n}-p\right\| \leq & \left\|x_{n}-T_{i}^{n} y_{n}\right\|+\left\|T_{i}^{n} y_{n}-p\right\| \\
\leq & \left\|x_{n}-T_{i}^{n} y_{n}\right\|+\left(1+\mu_{i n} M_{i}^{*}\right)\left(1+\tilde{\mu}_{i n} N_{i}^{*}\right)\left\|y_{n}-p\right\| \\
& +\tilde{\mu}_{i n}\left(1+\mu_{i n} M_{i}^{*}\right) \varphi_{i}\left(N_{i}\right)+\tilde{\lambda}_{i n}\left(1+\mu_{i n} M_{i}^{*}\right)+\mu_{i n} \phi_{i}\left(M_{i}\right)+\lambda_{i n},
\end{aligned}
$$


Journal of Applied Mathematics

which implies

$$
\begin{aligned}
\left\|x_{n}-p\right\|-\left\|x_{n}-T_{i}^{n} y_{n}\right\| \leq & \left(1+\mu_{i n} M_{i}^{*}\right)\left(1+\tilde{\mu}_{i n} N_{i}^{*}\right)\left\|y_{n}-p\right\| \\
& +\tilde{\mu}_{i n}\left(1+\mu_{i n} M_{i}^{*}\right) \varphi_{i}\left(N_{i}\right)+\tilde{\lambda}_{i n}\left(1+\mu_{i n} M_{i}^{*}\right) \\
& +\mu_{i n} \phi_{i}\left(M_{i}\right)+\lambda_{i n} .
\end{aligned}
$$

The last inequality with (3.22), (3.40) yields

$$
\liminf _{n \rightarrow \infty}\left\|y_{n}-p\right\|=d
$$

Combining (3.44) with (3.37), we get

$$
\lim _{n \rightarrow \infty}\left\|y_{n}-p\right\|=d
$$

Again from (1.27), we can see that

$$
\left\|y_{n}-p\right\|=\left\|\beta_{0 n}\left(x_{n}-p\right)+\sum_{i=1}^{m} \beta_{i n}\left(I_{i}^{n} x_{n}-p\right)\right\| \longrightarrow d, \quad n \longrightarrow \infty
$$

From (3.12) and (3.22), one finds

$$
\limsup _{n \rightarrow \infty}\left\|I_{i}^{n} x_{n}-p\right\| \leq \limsup _{n \rightarrow \infty}\left(\left(1+\tilde{\mu}_{i n} N_{i}^{*}\right)\left\|x_{n}-p\right\|+\tilde{\mu}_{i n} \varphi_{i}\left(N_{i}\right)+\tilde{\lambda}_{i n}\right)=d
$$

for all $i=\overline{1, m}$. Now applying Lemma 3.2 to (3.46), we obtain

$$
\lim _{n \rightarrow \infty}\left\|x_{n}-I_{i}^{n} x_{n}\right\|=0,
$$

for all $i=\overline{1, m}$. We then have

$$
\lim _{n \rightarrow \infty}\left\|y_{n}-x_{n}\right\|=\lim _{n \rightarrow \infty}\left\|\sum_{i=1}^{m} \beta_{i n}\left(I_{i}^{n} x_{n}-x_{n}\right)\right\|=0 .
$$

Consider

$$
\begin{aligned}
\left\|x_{n}-T_{i}^{n} x_{n}\right\| \leq & \left\|x_{n}-T_{i}^{n} y_{n}\right\|+\left\|T_{i}^{n} y_{n}-T_{i}^{n} x_{n}\right\| \\
\leq & \left\|x_{n}-T_{i}^{n} y_{n}\right\|+\left(1+\mu_{i n} M_{i}^{*}\right)\left(1+\tilde{\mu}_{i n} N_{i}^{*}\right)\left\|y_{n}-x_{n}\right\| \\
& +\left(1+\mu_{i n} M_{i}^{*}\right)\left(\tilde{\mu}_{i n} \varphi_{i}\left(N_{i}\right)+\tilde{\lambda}_{i n}\right)+\mu_{i n} \phi_{i}\left(M_{i}\right)+\lambda_{i n},
\end{aligned}
$$


for all $i=\overline{1, m}$. Then from (3.40) and (3.49), we get

$$
\lim _{n \rightarrow \infty}\left\|x_{n}-T_{i}^{n} x_{n}\right\|=0,
$$

for all $i=\overline{1, m}$.

Now we are ready to formulate a main result concerning strong convergence of the sequence $\left\{x_{n}\right\}$.

Theorem 3.7. Let $X$ be a uniformly convex real Banach space, and let $K$ be a nonempty closed-convex subset of $X$. Let $\left\{T_{i}\right\}_{i=1}^{m}: K \rightarrow K$ be a finite family of total asymptotically $I_{i}$-nonexpansive continuous mappings with sequences $\left\{\mu_{i n}\right\}_{n=1}^{\infty},\left\{\lambda_{i n}\right\}_{n=1}^{\infty}$, where $i=\overline{1, m}$, and let $\left\{I_{i}\right\}_{i=1}^{m}: K \rightarrow K$ be a finite family of total asymptotically nonexpansive continuous mappings with sequences $\left\{\tilde{\mu}_{i n}\right\}_{n=1}^{\infty},\left\{\tilde{\lambda}_{i n}\right\}_{n=1}^{\infty}$, where $i=\overline{1, m}$, such that $F:=\bigcap_{i=1}^{m}\left(F\left(T_{i}\right) \cap F\left(I_{i}\right)\right) \neq \emptyset$. Suppose that $\sum_{n=1}^{\infty} \mu_{i n}<\infty, \sum_{n=1}^{\infty} \lambda_{i n}<\infty$, $\sum_{n=1}^{\infty} \tilde{\mu}_{i n}<\infty, \sum_{n=1}^{\infty} \tilde{\lambda}_{i n}<\infty$ for all $i=\overline{1, m}$, and $\left\{\alpha_{j n}\right\}_{n=1}^{\infty},\left\{\beta_{j n}\right\}_{n=1}^{\infty}$ are sequences with $\left\{\alpha_{j n}\right\}_{n=1}^{\infty} \subset$ $\left[\alpha_{*}, \alpha^{*}\right]$ and $\left\{\beta_{j n}\right\}_{n=1}^{\infty} \subset\left[\beta_{*}, \beta^{*}\right]$, for all $j=\overline{0, m}$, here $0<\alpha_{*}<\alpha^{*}<1,0<\beta_{*}<\beta^{*}<1$, and there exist $M_{i}, M_{i}^{*}, N_{i}, N_{i}^{*}>0, i=\overline{1, m}$ such that $\phi_{i}\left(\xi_{i}\right) \leq M_{i}^{*} \xi_{i}$, for all $\xi_{i} \geq M_{i}$ and $\varphi_{i}\left(\zeta_{i}\right) \leq N_{i}^{*} \zeta_{i}$ for all $\zeta_{i} \geq N_{i}$, where $i=\overline{1, m}$. If at least one mapping of the mappings $\left\{T_{i}\right\}_{i=1}^{m}$ and $\left\{I_{i}\right\}_{i=1}^{m}$ is compact, then the explicitly iterative sequence $\left\{x_{n}\right\}$ defined by (1.27) converges strongly to a common fixed point of $\left\{T_{i}\right\}_{i=1}^{m}$ and $\left\{I_{i}\right\}_{i=1}^{m}$.

Proof. Without any loss of generality, we may assume that $T_{1}$ is compact. This means that there exists a subsequence $\left\{T_{1}^{n_{k}} x_{n_{k}}\right\}_{k=1}^{\infty}$ of $\left\{T_{1}^{n} x_{n}\right\}_{n=1}^{\infty}$ such that $\left\{T_{1}^{n_{k}} x_{n_{k}}\right\}_{k=1}^{\infty}$ converges strongly to $x^{*} \in K$. Then from (3.34), we have that $\left\{x_{n_{k}}\right\}_{k=1}^{\infty}$ converges strongly to $x^{*}$. Also from (3.34), we obtain that $\left\{T_{i}^{n_{k}} x_{n_{k}}\right\}_{k=1}^{\infty}$ converges strongly to $x^{*}$, for all $i=\overline{2, m}$. Since $\left\{T_{i}\right\}_{i=1}^{m}$ are continuous mappings, so $\left\{T_{i}^{n_{k}+1} x_{n_{k}}\right\}_{k=1}^{\infty}$ converges strongly to $T_{i} x^{*}$, for all $i=\overline{1, m}$. On the other hand, from (3.35) and continuousness of $\left\{I_{i}\right\}_{i=1}^{m}$, we obtain that $\left\{I_{i}^{n_{k}} x_{n_{k}}\right\}_{k=1}^{\infty}$ converges strongly to $x^{*}$, and $\left\{I_{i}^{n_{k}+1} x_{n_{k}}\right\}_{k=1}^{\infty}$ converges strongly to $I_{i} x^{*}$, for all $i=\overline{1, m}$. Due to (3.41), $\left\{\left\|x_{n_{k}+1}-x_{n_{k}}\right\|\right\}$ converges to 0 , as $k \rightarrow \infty$. Then, $\left\{x_{n_{k}+1}\right\}_{k=1}^{\infty}$ converges strongly to $x^{*}$ and moreover, (3.13) and (3.12) imply that $\left\{\left\|T_{i}^{n_{k}+1} x_{n_{k}+1}-T_{i}^{n_{k}+1} x_{n_{k}}\right\|\right\}$ and $\left\{\left\|I_{i}^{n_{k}+1} x_{n_{k}+1}-I_{i}^{n_{k}+1} x_{n_{k}}\right\|\right\}$ converge to 0 , as $k \rightarrow \infty$, for all $i=\overline{1, m}$. From (3.34), (3.35), it yields that $\left\|x_{n_{k}+1}-T_{i}^{n_{k}+1} x_{n_{k}+1}\right\|$ and $\left\|x_{n_{k}+1}-I_{i}^{n_{k}+1} x_{n_{k}+1}\right\|$ converge to 0 as $k \rightarrow \infty$, for all $i=\overline{1, m}$. Observe that

$$
\begin{aligned}
\left\|x^{*}-T_{i} x^{*}\right\| \leq & \left\|x^{*}-x_{n_{k}+1}\right\|+\left\|x_{n_{k}+1}-T_{i}^{n_{k}+1} x_{n_{k}+1}\right\| \\
& +\left\|T_{i}^{n_{k}+1} x_{n_{k}+1}-T_{i}^{n_{k}+1} x_{n_{k}}\right\|+\left\|T_{i}^{n_{k}+1} x_{n_{k}}-T_{i} x^{*}\right\|, \\
\left\|x^{*}-I_{i} x^{*}\right\| \leq & \left\|x^{*}-x_{n_{k}+1}\right\|+\left\|x_{n_{k}+1}-I_{i}^{n_{k}+1} x_{n_{k}+1}\right\| \\
& +\left\|I_{i}^{n_{k}+1} x_{n_{k}+1}-I_{i}^{n_{k}+1} x_{n_{k}}\right\|+\left\|I_{i}^{n_{k}+1} x_{n_{k}}-I_{i} x^{*}\right\|,
\end{aligned}
$$

for all $i=\overline{1, m}$. Taking limit as $k \rightarrow \infty$, we have that $x^{*}=T_{i} x^{*}$ and $x^{*}=I_{i} x^{*}$, for all $i=\overline{1, m}$, which means $x^{*} \in F$. However, by Lemma 3.4, the $\operatorname{limit}_{\lim } \operatorname{li\infty }_{n}\left\|x_{n}-x^{*}\right\|$ exists, then

$$
\lim _{n \rightarrow \infty}\left\|x_{n}-x^{*}\right\|=\lim _{n_{k} \rightarrow \infty}\left\|x_{n_{k}}-x^{*}\right\|=0,
$$

which means $\left\{x_{n}\right\}$ converges strongly to $x^{*} \in F$. This completes the proof. 
Remark 3.8. If one has that all $I_{i}$ are identity mappings, then the obtained results recover and correctly prove the main result of [24].

Remark 3.9. Suppose that we are given two families $\left\{T_{i}\right\}_{i=1}^{m}: K \rightarrow K$ and $\left\{S_{i}\right\}_{i=1}^{m}: K \rightarrow K$ of total asymptotically nonexpansive continuous mappings such that $\bigcap_{i=1}^{m}\left(F\left(T_{i}\right) \cap F\left(S_{i}\right)\right) \neq \emptyset$. Define the following explicit iterative process:

$$
\begin{aligned}
x_{0} & \in K, \\
x_{n+1} & =\alpha_{0 n} x_{n}+\sum_{i=1}^{m} \alpha_{i n} T_{i}^{n} y_{n}+\alpha_{m+1, n} u_{n} \\
y_{n} & =\beta_{0 n} x_{n}+\sum_{i=1}^{m} \beta_{i n} S_{i}^{n} x_{n}+\beta_{m+1, n} v_{n}
\end{aligned}
$$

such that $\sum_{j=0}^{m+1} \alpha_{j n}=1$ and $\sum_{j=0}^{m+1} \beta_{j n}=1$.

Under suitable conditions, by the same argument and methods used above, one can prove, with either little mirror or no modifications, the strong convergence of the explicit iterative process defined by (3.54) to a common fixed point of the given families.

Remark 3.10. Let $\left\{T_{i}\right\}_{i=1}^{m}: K \rightarrow K$ be a finite family of total asymptotically nonexpansive continuous mappings with sequences $\left\{\mu_{i n}\right\}_{n=1}^{\infty},\left\{\lambda_{i n}\right\}_{n=1}^{\infty}$, where $i=\overline{1, m}$. It is clear for each operator $T_{i}$ that one has

$$
\left\|T_{i}^{n} x-T_{i}^{n} y\right\| \leq\left\|T_{i}^{n} x-T_{i}^{n} y\right\|+\mu_{i n}\left\|T_{i}^{n} x-T_{i}^{n} y\right\|
$$

and this means that $T_{i}$ is total asymptotically $T_{i}$-nonexpansive mappings with sequence $\left\{\mu_{i n}\right\}_{n=1}^{\infty}$ and the function $\phi(\lambda)=\lambda$. Hence, our iteration scheme can be written as follows:

$$
\begin{aligned}
x_{0} & \in K, \\
x_{n+1} & =\alpha_{0 n} x_{n}+\sum_{i=1}^{m} \alpha_{i n} T_{i}^{n} y_{n}, \\
y_{n} & =\beta_{0 n} x_{n}+\sum_{i=1}^{m} \beta_{i n} T_{i}^{n} x_{n},
\end{aligned}
$$

where $\left\{\alpha_{j n}\right\}_{n=1}^{\infty},\left\{\beta_{j n}\right\}_{n=1}^{\infty}$ in $(0,1),(j=\overline{0, m})$ with $\sum_{j=0}^{m} \alpha_{j n}=1, \sum_{j=0}^{m} \beta_{j n}=1$.

The defined scheme is a new iterative method generalizing one given in [24]. So, according to our main results for the defined sequence $\left\{x_{n}\right\}$ (see (3.56)), we obtain strong convergence theorems. On the other hand, playing with numbers $\left\{\alpha_{j n}\right\}_{n=1}^{\infty},\left\{\beta_{j n}\right\}_{n=1}^{\infty}$ and by means of the defined method, one may introduce lots of different schemes. All of the them strongly converge to a common fixed point of $\left\{T_{i}\right\}_{i=1}^{m}$. Moreover, the recursion formula (3.56) is much simpler than the others studied earlier for this problem [21, 23, 29, 30, 32, 35-38]. Therefore, all presented results here generalize, unify, and extend the corresponding main results of the mentioned papers. Note that one can consider the method (1.27) with errors, 
and all the theorems could be carried over for such iteration scheme as well with little or no modifications.

We stress that all the theorems of this paper carry over to the class of total asymptotically quasi-I-nonexpansive mappings (see [24]), [39] with little or no modifications.

\section{Acknowledgments}

A part of this work was done at the Abdus Salam International Center for Theoretical Physics (ICTP), Trieste, Italy. The first named author (F. Mukhamedov) thanks the ICTP for providing financial support during his visit as a Junior Associate at the centre. The authors also acknowledge the Malaysian Ministry of Science, Technology and Innovation Grant no. 01-01-08-SF0079.

\section{References}

[1] F. E. Browder, "Nonexpansive nonlinear operators in a Banach space," Proceedings of the National Academy of Sciences of the United States of America, vol. 54, pp. 1041-1044, 1965.

[2] F. E. Browder, "Convergence of approximants to fixed points of nonexpansive non-linear mappings in Banach spaces," Archive for Rational Mechanics and Analysis, vol. 24, pp. 82-90, 1967.

[3] K. Goebel and W. A. Kirk, Topics in Metric Fixed Point Theory, vol. 28 of Cambridge Studies in Advanced Mathematics, Cambridge University Press, Cambridge, UK, 1990.

[4] C. Chidume, Geometric Properties of Banach Spaces and Nonlinear Iterations, vol. 1965 of Lecture Notes in Mathematics, Springer, London, UK, 2009.

[5] K. Goebel and W. A. Kirk, "A fixed point theorem for asymptotically nonexpansive mappings," Proceedings of the American Mathematical Society, vol. 35, pp. 171-174, 1972.

[6] R. Bruck, T. Kuczumow, and S. Reich, "Convergence of iterates of asymptotically nonexpansive mappings in Banach spaces with the uniform Opial property," Colloquium Mathematicum, vol. 65, no. 2, pp. 169-179, 1993.

[7] W. A. Kirk, "Fixed point theorems for non-Lipschitzian mappings of asymptotically nonexpansive type," Israel Journal of Mathematics, vol. 17, pp. 339-346, 1974.

[8] G. E. Kim and T. H. Kim, "Mann and Ishikawa iterations with errors for non-Lipschitzian mappings in Banach spaces," Computers \& Mathematics with Applications, vol. 42, no. 12, pp. 1565-1570, 2001.

[9] R. E. Bruck, "Asymptotic behavior of nonexpansive mappings," in Fixed Points and Nonexpansive Mappings, vol. 18 of Contemporary Mathematics, pp. 1-47, American Mathematical Society, Providence, RI, USA, 1983.

[10] Q. Liu, "Iterative sequences for asymptotically quasi-nonexpansive mappings," Journal of Mathematical Analysis and Applications, vol. 259, no. 1, pp. 1-7, 2001.

[11] R. Wittmann, "Approximation of fixed points of nonexpansive mappings," Archiv der Mathematik, vol. 58, no. 5, pp. 486-491, 1992.

[12] S. Reich, "Strong convergence theorems for resolvents of accretive operators in Banach spaces," Journal of Mathematical Analysis and Applications, vol. 75, no. 1, pp. 287-292, 1980.

[13] J. Gornicki, "Weak convergence theorems for asymptotically nonexpansive mappings in uniformly convex Banach spaces," Commentationes Mathematicae Universitatis Carolinae, vol. 30, no. 2, pp. 249$252,1989$.

[14] J. Schu, "Weak and strong convergence to fixed points of asymptotically nonexpansive mappings," Bulletin of the Australian Mathematical Society, vol. 43, no. 1, pp. 153-159, 1991.

[15] N. Shioji and W. Takahashi, "Strong convergence theorems for asymptotically nonexpansive semigroups in Hilbert spaces," Nonlinear Analysis A, vol. 34, no. 1, pp. 87-99, 1998.

[16] K.-K. Tan and H. K. Xu, "Approximating fixed points of nonexpansive mappings by the Ishikawa iteration process," Journal of Mathematical Analysis and Applications, vol. 178, no. 2, pp. 301-308, 1993.

[17] S.-S. Chang, R. P. Agarwal, and Y. J. Cho, "Strong convergence of iterative sequences for asymptotically nonexpansive mappings in Banach spaces," Dynamic Systems and Applications, vol. 14, no. 3-4, pp. 447-454, 2005. 
[18] S. S. Chang, Y. J. Cho, and Y. X. Tian, "Strong convergence theorems of Reich type iterative sequence for non-self asymptotically nonexpansive mappings," Taiwanese Journal of Mathematics, vol. 11, no. 3, pp. 729-743, 2007.

[19] Y. J. Cho, J. I. Kang, and H. Zhou, "Approximating common fixed points of asymptotically nonexpansive mappings," Bulletin of the Korean Mathematical Society, vol. 42, no. 4, pp. 661-670, 2005.

[20] Y. J. Cho, H. Zhou, and G. Guo, "Weak and strong convergence theorems for three-step iterations with errors for asymptotically nonexpansive mappings," Computers $\mathcal{E}$ Mathematics with Applications, vol. 47, no. 4-5, pp. 707-717, 2004.

[21] Ya. I. Alber, C. E. Chidume, and H. Zegeye, "Approximating fixed points of total asymptotically nonexpansive mappings," Fixed Point Theory and Applications, vol. 2006, Article ID 10673, 20 pages, 2006.

[22] N. Shahzad, "Generalized I-nonexpansive maps and best approximations in Banach spaces," Demonstratio Mathematica, vol. 37, no. 3, pp. 597-600, 2004.

[23] C. E. Chidume and E. U. Ofoedu, "Approximation of common fixed points for finite families of total asymptotically nonexpansive mappings," Journal of Mathematical Analysis and Applications, vol. 333, no. 1, pp. 128-141, 2007.

[24] C. E. Chidume and E. U. Ofoedu, "A new iteration process for approximation of common fixed points for finite families of total asymptotically nonexpansive mappings," International Journal of Mathematics and Mathematical Sciences, vol. 2009, Article ID 615107, 17 pages, 2009.

[25] Y. J. Cho, N. Hussain, and H. K. Pathak, "Approximation of nearest common fixed points of asymptotically I-nonexpansive mappings in Banach spaces," Korean Mathematical Society. Communications, vol. 26, no. 3, pp. 483-498, 2011.

[26] B. H. Rhodes and S. Temir, " Convergebce thorems for I-nonexpansive mapping," International Journal of Mathematics and Mathematical Sciences, vol. 2006, Article ID 63435, 4 pages, 2006.

[27] P. Kumam, W. Kumethong, and N. Jewwaiworn, "Weak convergence theorems of three-step Noor iterative scheme for I-quasi-nonexpansive mappings in Banach spaces," Applied Mathematical Sciences, vol. 2, no. 57-60, pp. 2915-2920, 2008.

[28] S. Temir and O. Gul, "Convergence theorem for I-asymptotically quasi-nonexpansive mapping in Hilbert space," Journal of Mathematical Analysis and Applications, vol. 329, no. 2, pp. 759-765, 2007.

[29] F. Gu, "Some convergence theorems of non-implicit iteration process with errors for a finite families of I-asymptotically nonexpansive mappings," Applied Mathematics and Computation, vol. 216, no. 1, pp. 161-172, 2010.

[30] S. Temir, "On the convergence theorems of implicit iteration process for a finite family of $I$ asymptotically nonexpansive mappings," Journal of Computational and Applied Mathematics, vol. 225, no. 2, pp. 398-405, 2009.

[31] S. Temir, "Convergence of iterative process for generalized I-asymptotically quasi-nonexpansive mappings," Thai Journal of Mathematics, vol. 7, no. 2, pp. 367-379, 2009.

[32] D. R. Sahu, "Fixed points of demicontinuous nearly Lipschitzian mappings in Banach spaces," Commentationes Mathematicae Universitatis Carolinae, vol. 46, no. 4, pp. 653-666, 2005.

[33] N. Shahzad and A. Udomene, "Approximating common fixed points of two asymptotically quasinonexpansive mappings in Banach spaces," Fixed Point Theory and Applications, vol. 2006, Article ID 18909, 10 pages, 2006.

[34] E. Zeidler, Nonlinear Functional Analysis and Its Applications. I, Fixed-Point Theorems, Springer, New York, NY, USA, 1986.

[35] Y. Alber, R. Espínola, and P. Lorenzo, "Strongly convergent approximations to fixed points of total asymptotically nonexpansive mappings," Acta Mathematica Sinica, vol. 24, no. 6, pp. 1005-1022, 2008.

[36] F. Mukhamedov and M. Saburov, "Weak and strong convergence of an implicit iteration process for an asymptotically quasi-I-nonexpansive mapping in Banach space," Fixed Point Theory and Applications, vol. 2010, Article ID 719631, 13 pages, 2010.

[37] W. Guo and Y. J. Cho, "On the strong convergence of the implicit iterative processes with errors for a finite family of asymptotically nonexpansive mappings," Applied Mathematics Letters, vol. 21, no. 10, pp. 1046-1052, 2008.

[38] H. Y. Zhou, Y. J. Cho, and S. M. Kang, "A new iterative algorithm for approximating common fixed points for asymptotically nonexpansive mappings," Fixed Point Theory and Applications, vol. 2007, Article ID 64874, 10 pages, 2007.

[39] J. Zhao, S. He, and G. Liu, "Strong convergence theorems for generalized asymptotically quasinonexpansive mappings," Journal of Applied Mathematics and Computing, vol. 30, no. 1-2, pp. 53-64, 2009. 


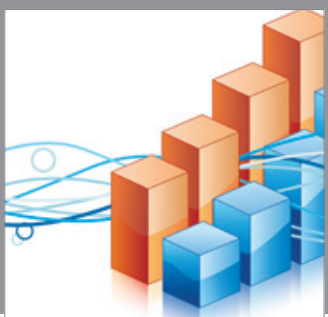

Advances in

Operations Research

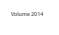

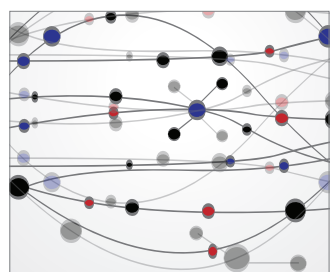

\section{The Scientific} World Journal
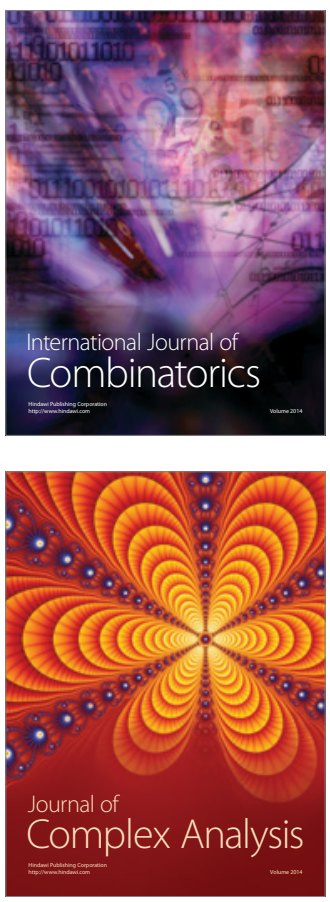

International Journal of

Mathematics and

Mathematical

Sciences
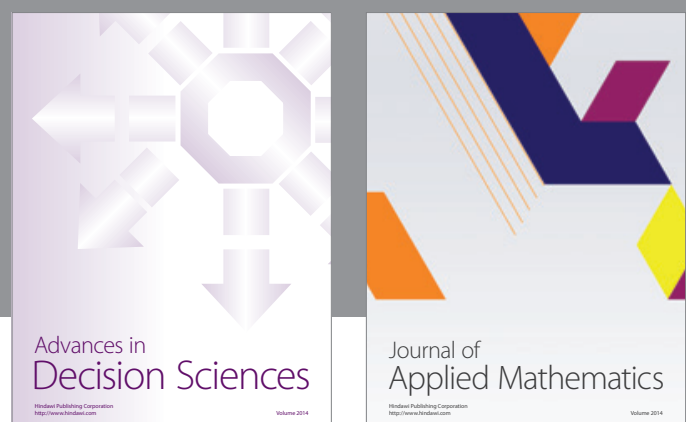

Journal of

Applied Mathematics
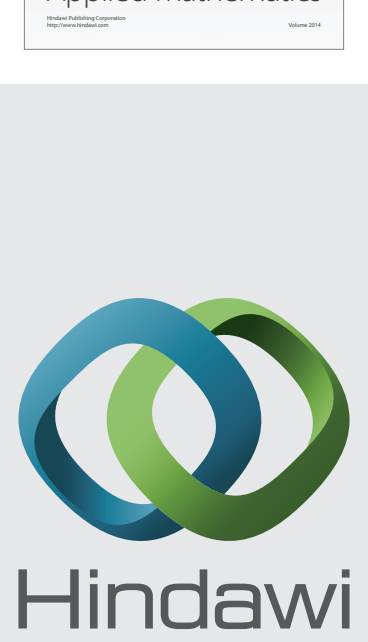

Submit your manuscripts at http://www.hindawi.com
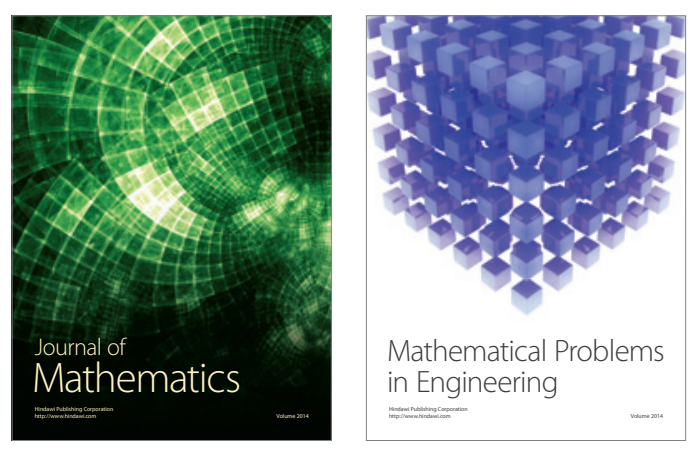

Mathematical Problems in Engineering
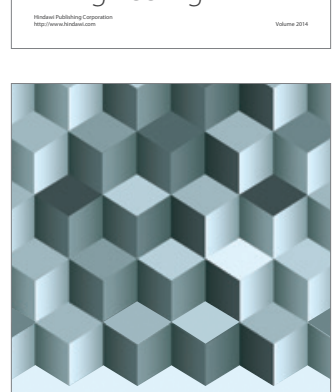

Journal of

Function Spaces
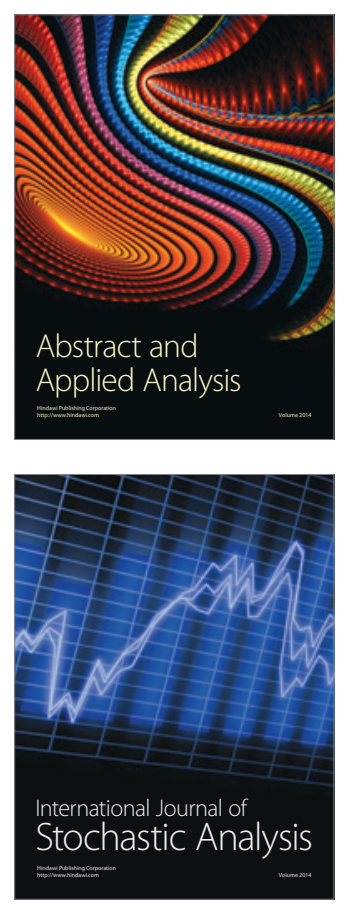

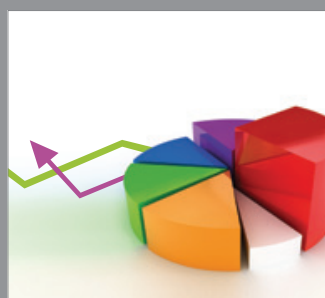

ournal of

Probability and Statistics

Promensencen
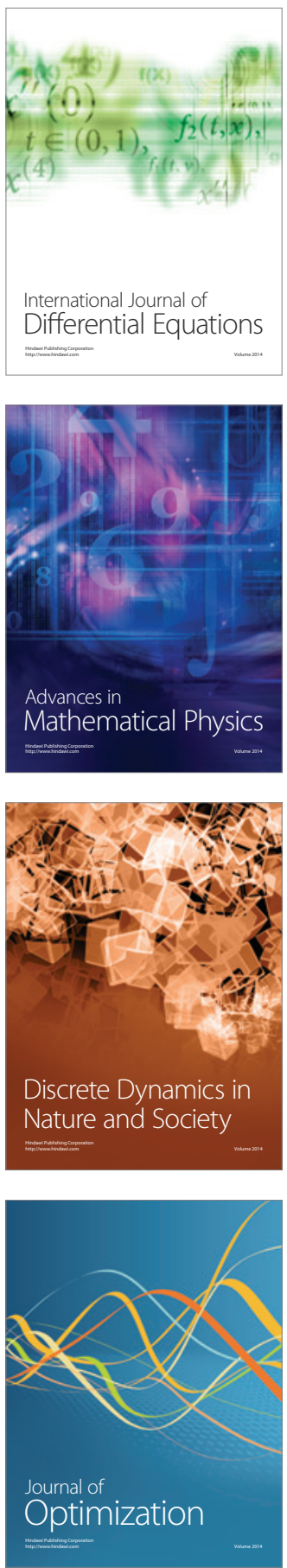